\title{
Proteomic assessment of a cell model of spinal muscular atrophy
}

\author{
Chia-Yen $\mathrm{Wu}^{1+}$, Dosh Whye ${ }^{2+}$, Lisa Glazewski ${ }^{3}$, Leila Choe ${ }^{4}$, Douglas Kerr ${ }^{5}$, Kelvin H Lee ${ }^{4}$, Robert W Mason ${ }^{1,3,6}$, \\ Wenlan Wang ${ }^{3,6^{*}}$
}

\begin{abstract}
Background: Deletion or mutation(s) of the survival motor neuron 1 (SMN1) gene causes spinal muscular atrophy (SMA), a neuromuscular disease characterized by spinal motor neuron death and muscle paralysis. Complete loss of the SMN protein is embryonically lethal, yet reduced levels of this protein result in selective death of motor neurons. Why motor neurons are specifically targeted by SMN deficiency remains to be determined. In this study, embryonic stem (ES) cells derived from a severe SMA mouse model were differentiated into motor neurons in vitro by addition of retinoic acid and sonic hedgehog agonist. Proteomic and western blot analyses were used to probe protein expression alterations in this cell-culture model of SMA that could be relevant to the disease.
\end{abstract}

Results: When ES cells were primed with Noggin/fibroblast growth factors (bFGF and FGF-8) in a more robust neural differentiation medium for 2 days before differentiation induction, the efficiency of in vitro motor neuron differentiation was improved from $\sim 25 \%$ to $\sim 50 \%$. The differentiated ES cells expressed a pan-neuronal marker (neurofilament) and motor neuron markers ( $\mathrm{Hb9}$, Islet-1, and ChAT). Even though SMN-deficient ES cells had marked reduced levels of SMN ( 20\% of that in control ES cells), the morphology and differentiation efficiency for these cells are comparable to those for control samples. However, proteomics in conjunction with western blot analyses revealed 6 down-regulated and 14 up-regulated proteins with most of them involved in energy metabolism, cell stress-response, protein degradation, and cytoskeleton stability. Some of these activated cellular pathways showed specificity for either undifferentiated or differentiated cells. Increased p21 protein expression indicated that SMA ES cells were responding to cellular stress. Up-regulation of p21 was confirmed in spinal cord tissues from the same SMA mouse model from which the ES cells were derived.

Conclusion: SMN-deficient ES cells provide a cell-culture model for SMA. SMN deficiency activates cellular stress pathways, causing a dysregulation of energy metabolism, protein degradation, and cytoskeleton stability.

\section{Background}

Spinal muscular atrophy (SMA) is an autosomal recessive disorder with a prevalence of 1 in 6000 live births and a carrier incidence of 1 in 40-50 [1,2]. The hallmark of SMA is death of spinal motor neurons and progressive muscle atrophy [3]. Based on age of onset and clinical severity, childhood SMA has been classified into types I, II, and III [2,4]. Type I SMA is the most severe, resulting in the death of the child before the age of two, while type II and III individuals can live on into

\footnotetext{
* Correspondence: wwang@nemours.org

† Contributed equally

${ }^{3}$ Nemours Biomedical Research, Nemours/Alfred I. duPont Hospital for Children, Wilmington, DE, USA

Full list of author information is available at the end of the article
}

adulthood; however, they suffer from varying degrees of muscle paralysis and atrophy.

Genetic analyses of familial SMA indicate that the vast majority of SMA is caused by deletion or mutation(s) of the telomeric copy of the survival motor neuron 1 (SMN1) gene [5]. Complete loss of this gene in all species is lethal. In humans, a highly homologous centromeric copy of the $S M N$ gene, SMN2, enables patient survival, but it cannot completely compensate for the loss of SMN1 [6,7]. The encoded SMN protein has been shown to play an essential role in the assembly of small nuclear ribonucleoprotein (snRNP) complexes [8-10]. SMN appears to function in snRNP biogenesis by interacting with Gemins 2-8, and Unrip [8,11,12]. A correlation between snRNP assembly activity in the spinal cord
C Biomed Central

() 2011 Wu et al; licensee BioMed Central Ltd. This is an Open Access article distributed under the terms of the Creative Commons Attribution License (http://creativecommons.org/licenses/by/2.0), which permits unrestricted use, distribution, and reproduction in any medium, provided the original work is properly cited. 
of SMA mice and severity of the disease has been demonstrated [13]. Widespread pre-mRNA splicing defects have also been seen in many cells and tissues in an SMA mouse model, indicating that SMA may be a general splicing disorder [14].

Reduced levels of SMN in SMA patients and animal models result in selective death of motor neurons, indicating that SMN plays a more critical role in motor neurons. Consistent with this indication, SMN has been shown to localize to granules that are actively transported into neurites and growth cones [15]. Axonal SMN appears to associate with heterogenous nuclear ribonucleoprotein $\mathrm{R}$ (hnRNP R) and to be involved in the transport of $\beta$-actin mRNA [16]. Indeed, distal axons and growth cones of motor neurons from SMA mice have defects in neurite outgrowth and reduced levels of $\beta$-actin mRNA and protein [16]. Zebra fish motor neurons with SMN deficiency also exhibit shorter and/or abnormally branched axons $[17,18]$. Recent studies in SMA mouse models further identified pre-synaptic defects including poor arborization, intermediate filament aggregation, impaired synaptic vesicle release, and trunk denervation [19-24]. Collectively, these data support a specific function for SMN in motor neurons and neuromuscular junctions.

Several SMA mouse models have been developed in the past decade [24-27]. One severe SMA mouse model $\left(S M N 2^{+/+} \mathrm{Smn}^{-/-}\right)$most closely mimics human type I SMA in that it lacks the mouse $S m n$ gene but carries two copies of the human SMN2 gene [25]. The SMA pups with this genotype appear normal at birth, but at post-natal day 2 (P2), they develop SMA-like symptoms including reduced suckling, decreased movement, and labored breathing. The pups die by P6-7. The short lifespan in this SMA mouse prohibits wide use of this model for mechanistic studies or drug development for SMA. Thus, development of an in vitro cell-culture system from this transgenic mouse, that recapitulates motor neuron differentiation and the unique features of mature motor neurons such as extension of axons and formation of neuromuscular junctions, will enable us to study motor neuron-specific functions of SMN.

Embryonic stem (ES) cells are unique cells derived from the inner cell mass of the mammalian blastocyst. These cells are pluripotent, immortal, and can be differentiated into mature cell types in response to specific cues [28,29]. Generation of spinal neurons can be achieved by exposure of embryoid bodies (EBs) to retinoic acid (RA) and sonic hedgehog (Shh) or a hedgehog agonist [30,31]. Motor neurons differentiated via this protocol were found to extend axons and form synapses with target muscle when implanted in the spinal cord [31-34], thus confirming the power of this approach in generating mature neuronal subpopulations.
In this study, we report on the effects of the differentiation of ES cells derived from the severe SMA mouse model into motor neurons. We developed a new protocol to improve differentiation efficiency from $\sim 25 \%$ to $\sim 50 \%$. The differentiated motor neurons were characterized by immunofluorescence and western blotting of neuronal and motor neuron markers. Using proteomic techniques, we determined that multiple signaling pathways are dysregulated in SMA cells.

\section{Results}

In vitro motor neuron differentiation is enhanced by increasing neural patterning with Noggin and fibroblast growth factors

To establish a cell-culture model of SMA, we initially used the control ES line (HBG3; HB9::eGFP) to optimize in vitro conditions for differentiation of ES cells into motor neurons. Since HBG3 ES cells were derived from a transgenic mouse expressing eGFP under the control of motor neuron specific promoter $\mathrm{Hb} 9$ [31], the efficiency of differentiation can be monitored by measuring the population of $\mathrm{GFP}^{+}$cells. Initially, ES cells were propagated on mouse embryonic fibroblasts and differentiated by the addition of RA and a Shh agonist (smoothened agonist, SAG) using a previous published protocol [31]. Retinoic acid caudalizes neural progenitors, while Shh has a ventralizing effect, leading to differentiation into motor neurons [31]. We optimized concentrations of RA (0.001-2 $\mu \mathrm{M})$ and SAG (0.001-1 $\mu \mathrm{M})$ and found that a combination of $1 \mu \mathrm{M}$ RA and 1 $\mu \mathrm{M}$ SAG gave the best degree of differentiation ( 25\%). Purmorphamine, a compound that activates the hedgehog signaling pathway and directs motor neuron differentiation [35,36], was also tested at 1-2.5 $\mu \mathrm{M}$ concentrations in combination with $1 \mu \mathrm{M}$ RA, but the differentiation rate was always less than $20 \%$. In order to enhance the neuralization process, we primed the ES cells with the bone morphogenetic protein antagonist, Noggin, and with bFGF and FGF-8 (see Methods) prior to the 5-day induction period with RA and SAG (Figure 1A). Noggin is implicated in neural induction according to the default model of neurogenesis and results in the formation of anterior neural patterning, while FGF acts synergistically with Noggin in inducing neural tissue formation by promoting a posterior neural identity [37-40]. Priming ES cells with these two signaling molecules before differentiation induction significantly increased $\mathrm{GFP}^{+}$population from $24.8 \% \pm 8.1$ to $51 \% \pm 0.8 \%$ ( $\mathrm{n}=$ $3 ; p<0.01$, Student's $t$-test). The differentiated ES cells extend long processes when plated on poly-ornithine/ laminin/matrigel-coated dishes (Figure 1).

The differentiated cells were characterized by the expression of neuronal and motor neuron marker proteins. Western blotting shows that a pan-neuronal 
$\mathbf{A}$
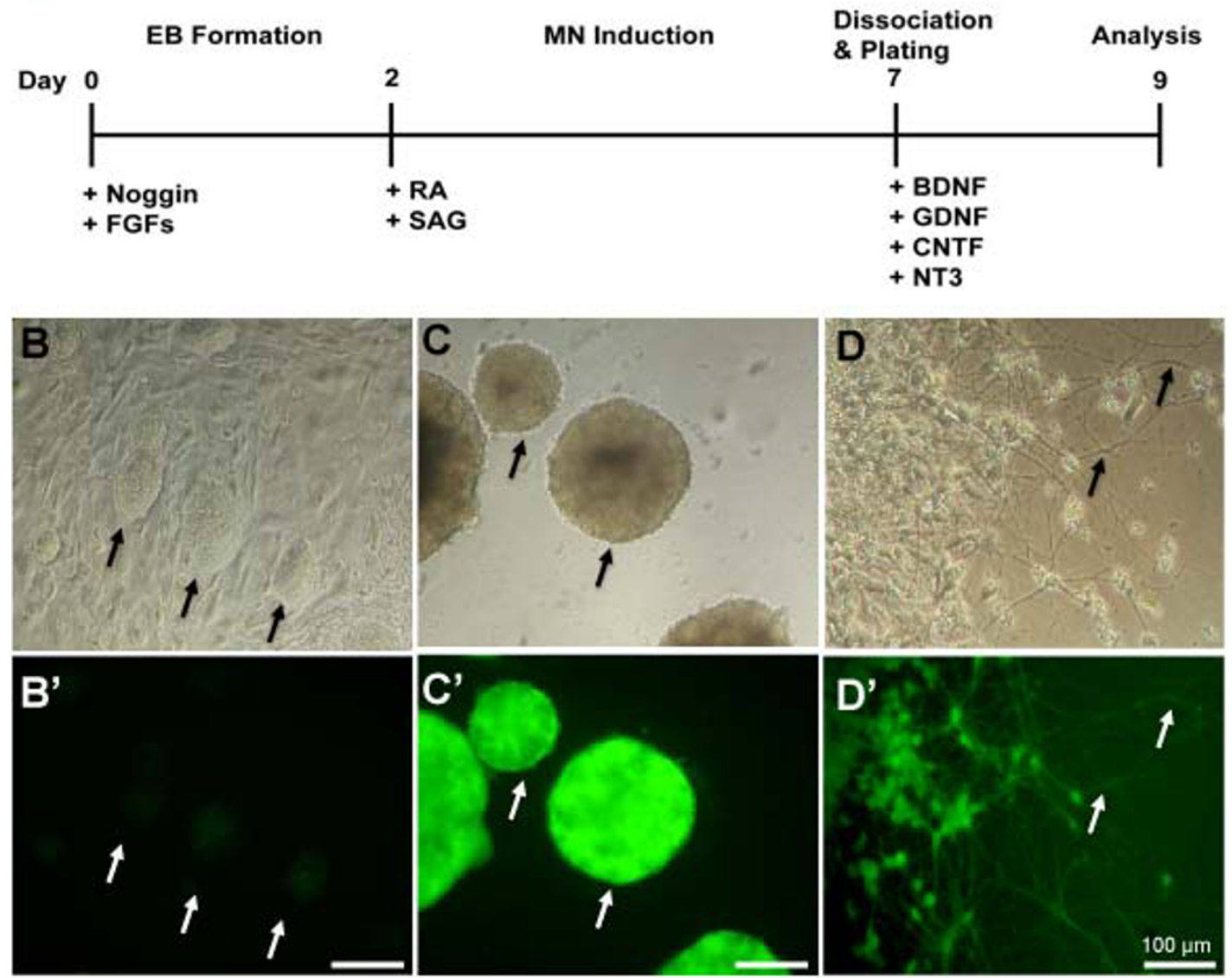

Figure 1 Differentiation of murine ES cells into motor neurons. The scheme outlines the process of motor neuron differentiation from ES cells (A). Murine ES cells (HBG3) were expanded on a layer of primary mouse embryonic fibroblasts. Undifferentiated stem cells form round clusters (arrows) as they proliferate on top of a feeding fibroblast layer, and they have weak GFP expression (B-B'). Stem cells were separated from the fibroblast layer and plated in low attachment dishes to allow for differentiation. Two-day-old stem cell aggregates (called embryoid bodies, EB, arrows) were induced to differentiate with $1 \mu \mathrm{M}$ retinoic acid and $1 \mu \mathrm{M}$ sonic hedgehog agonist SAG for 5 days. Differentiated ES cells have strong GFP expression (C-C'). When plated on poly-DL-ornithine/laminin/matrigel coated plates, the differentiated ES cells extend long neurites after 2 days in culture (D-D'). Representative phase contrast images for 1B-1D are shown on the top and corresponding fluorescent images are on the bottom. Scale bar $=200 \mu \mathrm{m}$ except as indicated. $\mathrm{MN}=$ motor neuron.

marker (neurofilament) and two motor neuron specific markers ( $\mathrm{Hb} 9$ and $\mathrm{ChAT})$ are expressed in differentiated ES cells but not in the undifferentiated ES cells (Figure 2A). Immunofluorescence staining shows that differentiated motor neurons are neurofilament, ChAT, and Islet-1 positive (Figure 2B).

\section{Proteomic analyses reveal altered protein expression in SMN-deficient ES cells}

The SMA ES cells were derived from a severe SMA transgenic mouse that lacks the murine $S m n$ gene but carries two copies of the human SMN2 gene [25]. Western blotting shows that SMA ES cells have a marked reduction in SMN protein ( $20 \%$ of control, Figure 3$)$. The SMN-interacting protein Gemin2 was also significantly decreased ( $40-50 \%$ of control, Figure 3 ). However, morphologically, SMA ES cells did not differ from the control ES cells (data not shown). Under the optimized differentiation conditions, SMN-deficient ES cells were differentiated into motor neurons in vitro as evidenced by neurofilament, $\mathrm{ChAT}$, and $\mathrm{Hb} 9$ expression (Figure 4A). Despite a drastic difference in SMN levels (Figure 3), control and SMA ES cells showed similar levels of neuronal and motor neuron marker expression after differentiation (Figure 4B). This is consistent with immunostaining results showing that $45-50 \%$ of differentiated cells were $\mathrm{Hb}^{+}$in both control and SMA ES cells.

To identify proteins that are up- or down-regulated in SMN-deficient ES cells, comparative two-dimensional SDS-polyacrylamide gel electrophoresis (SDS-PAGE) 


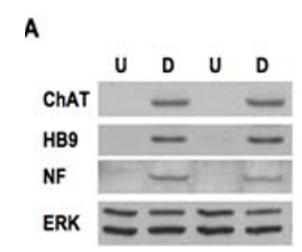

B

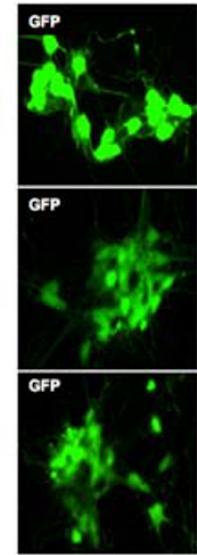

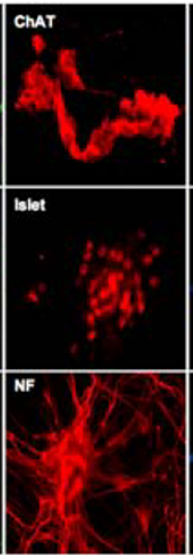

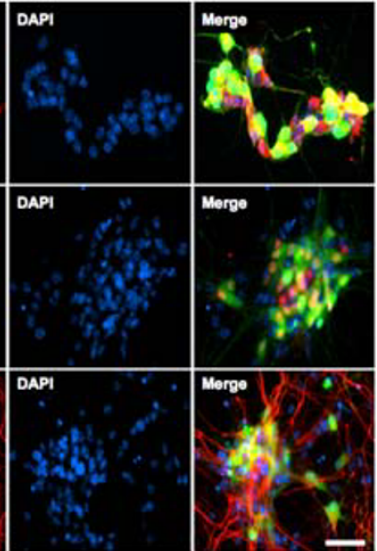

Figure 2 Characterization of motor neuron differentiation. HBG3 cells were induced to differentiate following the procedure as in 1A. Lysates from undifferentiated and differentiated cells were resolved on an SDS-PAGE and transferred to a membrane. The blot was probed with antibodies against pan-neuronal (neurofilament, NF) and motor neuron markers (Hb9 and ChAT). The same blot was stripped and re-probed with anti-ERK antibodies for protein loading control (A). Differentiated ES cells were dissociated and processed for indirect immunofluorescence staining for neurofilament (NF, in red), ChAT (in red), Islet-1 (in red), and DAPI (for nuclei in blue). Scale bar $=50 \mu \mathrm{m}$. $U=$ undifferentiated cells and $\mathrm{D}=$ differentiated cells.

\section{A}

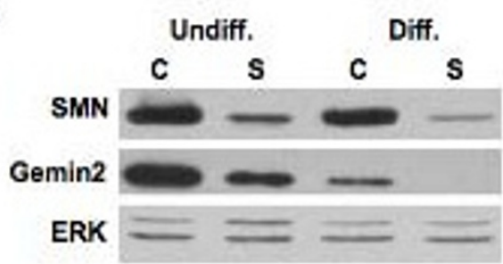

B

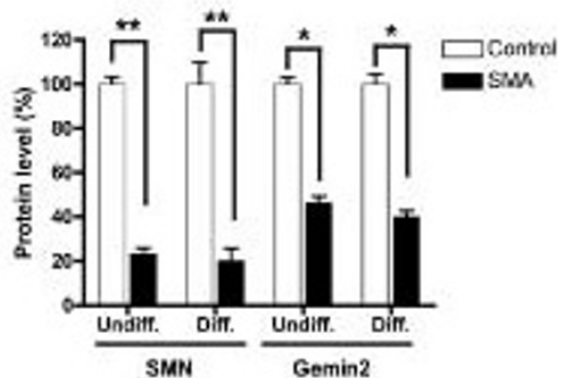

Figure 3 Reduced expressions of SMN and Gemin2 in SMNdeficient ES cells. Control (C) and SMA (S) ES cells were separated from feeding fibroblasts and allowed to differentiate in vitro in the presence of RA and SAG for 5 days. Both undifferentiated and differentiated cells were harvested and lysates were prepared. Equal amounts of total proteins were separated by SDS-PAGE, and SMN and Gemin2 were detected by western blotting. The same blot was stripped and re-probed with ERK antibodies for protein loading control (A). Signals were quantified, relative ratios of SMN or Gemin2 to ERK were calculated, and the mean value \pm SD of three independent experiments is presented here. Statistical analyses (Student's $t$ test) indicate that SMA cells have significantly reduced levels of SMN and Gemin2 expression (approximately 20\% of the control for SMN and 40-50\% for Gemin2) (** $p<0.01$ and * $p<$ $0.05)$ (B). Undiff. $=$ undifferentiated cells and Diff. $=$ differentiated cells.

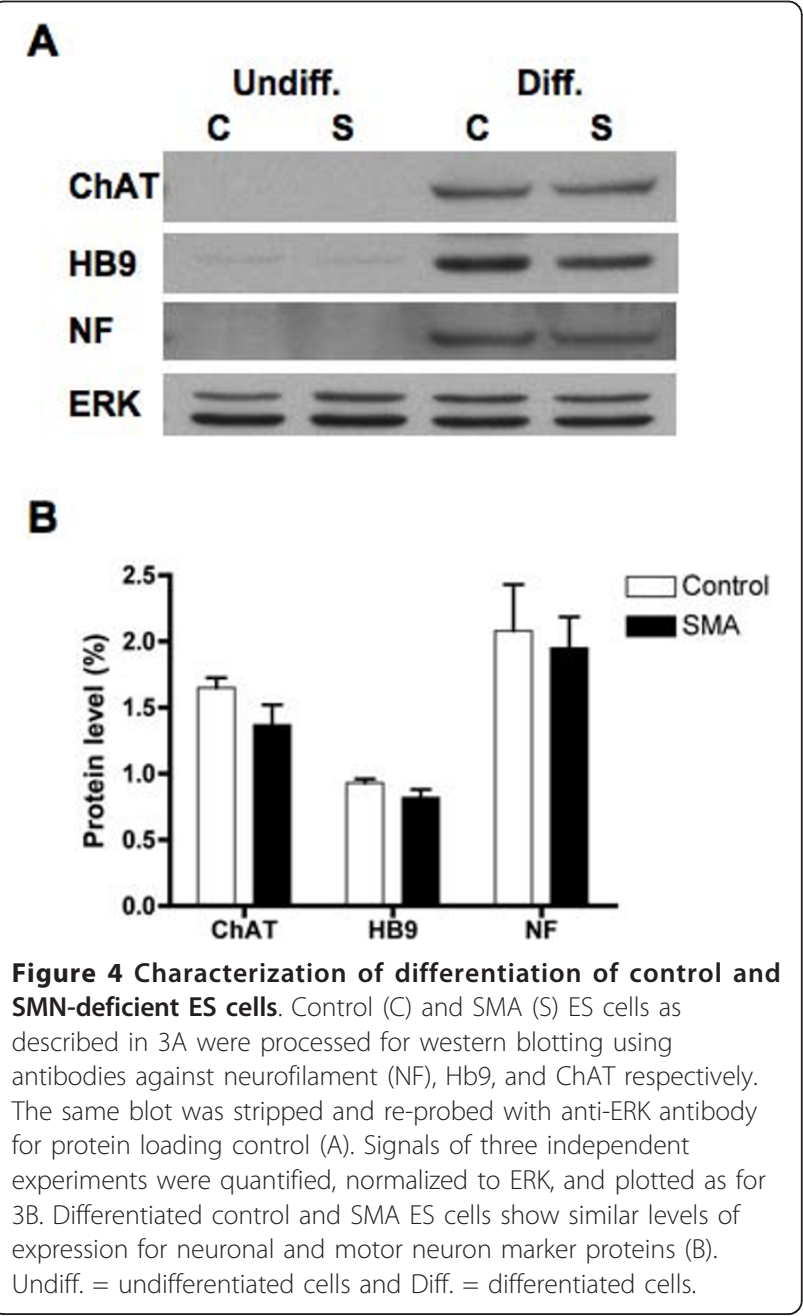


analyses of control and SMA ES cells were performed. The differences between control and SMN-depleted protein pools were analyzed using four separate control and SMA ES cell extracts and quantified using DeCyder software (Figure 5). A total of 1900 spots were identified. Spots that differed with a p-value less than 0.05 ( $t$-test) and that showed an average ratio of expression greater than or less than 1.5 were marked as points of interest (POI). For the undifferentiated ES cell samples, the 11 most abundant of the total 34 POIs were picked, and for the differentiated ES cell samples, the 14 most abundant of the total 32 POIs were picked. The protein identities of the picked POIs were determined by trypsin digestion and mass spectrometry. The majority of detected proteins were expressed at similar levels in control and SMA ES cells (Figure 5), but in our proteomic analyses, we were able to identify 4 out of 11 proteins in the undifferentiated samples and 11 out of 14 proteins in the differentiated samples that were significantly altered in SMA ES cells (Table 1). Most of the proteins identified as differentially expressed in SMA ES cells are involved in stress-responses (peroxiredoxin, stress induced phophoprotein, and chaperone proteins), cell metabolism (lactate dehydrogenase, glyoxalase 1, brain creatine kinase, and aldehyde dehydrogenase), protein turnover and ubiquitin modification (ubiquitin
C-terminal hydrolase L1), and cytoskeleton stability ( $\alpha$ tubulin and tropomyosin 3). Consistent with our finding, ubiquitin C-terminal hydrolase L1 is up-regulated in type I SMA fibroblasts [41], and tropomyosin 3 is upregulated while peroxiredoxin is down-regulated in the hippocampus of Smn-/-; SMN2+/+ mice [42]. We obtained antibodies to six of the differentially expressed proteins to validate the proteomic results. Western blot analysis confirmed that expression of peroxiredoxin 6 is increased in undifferentiated SMA cells and that lactate dehydrogenase and tropomyosin 3 are increased in differentiated SMA ES cells (Figure 6). However, no significant changes in levels of heat shock proteins $70 / 90$ or tubulin were detected by western blotting (Figure 7). Western blotting showed that expression of lactate dehydrogenase was increased in both undifferentiated and differentiated SMA ES cells, indicating increased metabolic activity in SMN-deficient cells.

\section{Western blot analysis reveals specific cell stress-response pathways activated in SMN-deficient ES cells}

Our proteomic study indicates that reduced levels of SMN increase expression of stress-response proteins (Table 1). Specific stress-response pathways dysregulated in SMNdeficient ES cells were analyzed by western blotting. We first analyzed levels of the stress-activated protein kinase/

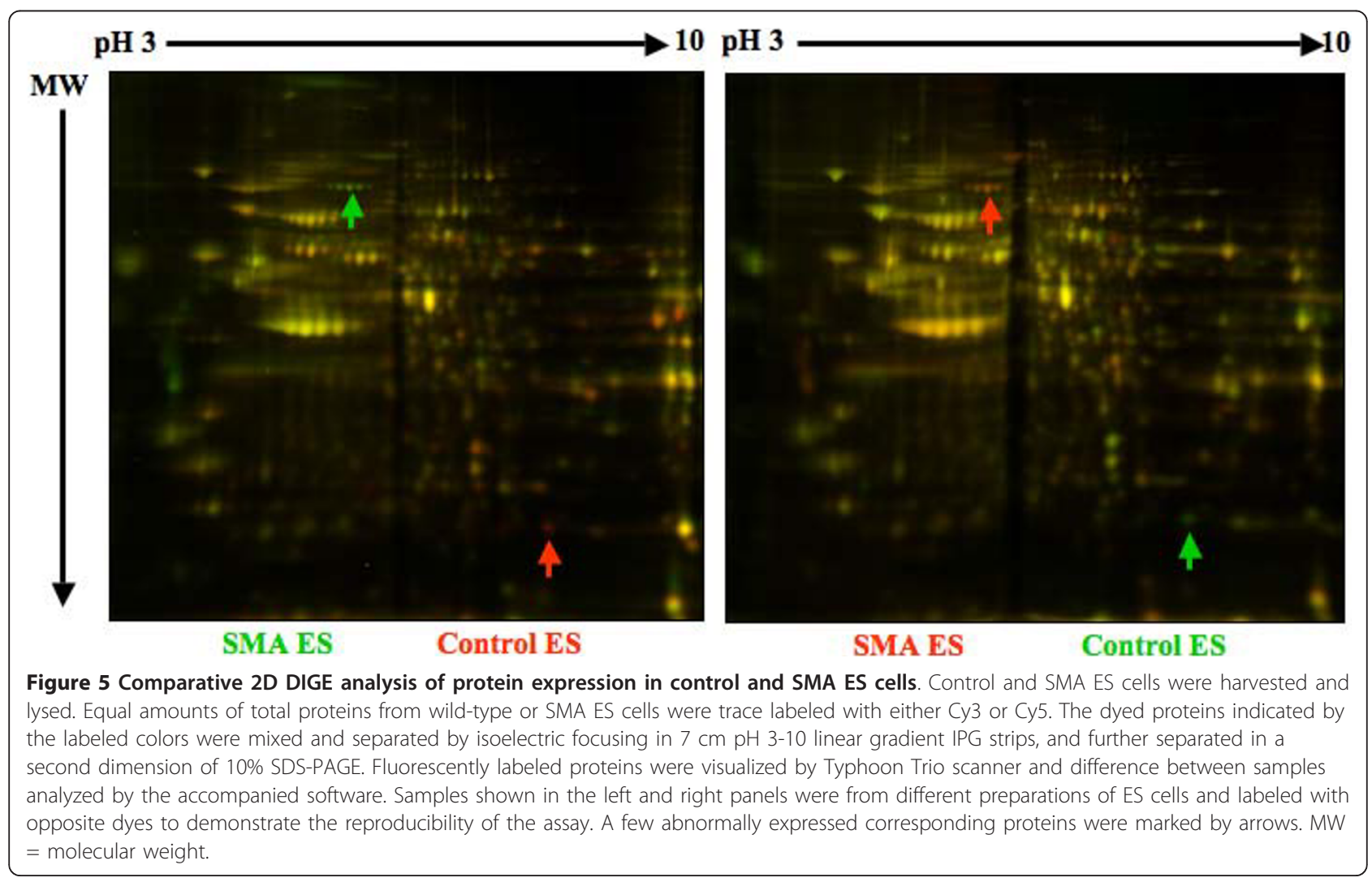


Table 1 Proteomic identification of dysregulated proteins in SMN-deficient ES cells

\begin{tabular}{lccl}
\hline Protein Name & Gene Symbol & Fold Change & Function \\
\hline Undifferentiated & & & \\
$\quad$ Chaperonin 6a & & & \\
FK506 binding protein 4 & Cct6a & +2.6 & Protein folding \\
Peroxiredoxin 6 & Fkbp4 & +1.75 & Protein folding and trafficking \\
Stress-induced-phosphoprotein 1 & Prdx1 & +1.6 & Redox regulation \\
& Stip1 & -1.75 & Adaptor protein for Hsp70 and Hsp90 \\
Differentiated & & & \\
Lactate dehydrogenase B & & & \\
Brain creatine kinase & Ldhb & +3.6 & Glycolysis \\
Glyoxalase 1 & Ckb & +1.8 & Cellular energy homeostasis \\
Tropomyosin 3 & Glo1 & +1.75 & Detoxification of glucose degradation products \\
Annexin A5 & Tpm3 & +1.75 & Stabilization of actin filaments \\
Ubiquitin carboxy-terminal hydrolase L1 & Anxa5 & +1.7 & Cell signaling, Inflammation; Growth/differentiation \\
Alpha-tubulin & Uchl1 & +1.7 & De-ubiquitination; Ubiquitin ligation; Mono-ubiquitin stabilizer \\
Aldehyde dehydrogenase & Tubala & +1.5 & Cytoskeletal protein \\
14-3-3 gamma & Aldh5a1 & -1.7 & Aldehyde oxidation \\
Heat shock protein 90B & Ywhag & -1.7 & Cell signaling; Check point control; Apoptosis \\
Heat shock protein 70K & Hsp90b1 & -1.8 & Chaperone protein \\
\hline
\end{tabular}

Jun-amino-terminal kinase SAPK/JNK and p38 MAP kinase in SMN-deficient ES cells. JNK and p38 MAP kinase are the two major stress-response pathways that are activated by a variety of cellular stresses including UV light and growth factors $[43,44]$. Levels of phosphorylated p38 were elevated in SMA ES cells ( 2.8 fold increase for the undifferentiated cells and $\sim 1.7$-fold increase for differentiated cells; Figure 8). Levels of phosphorylated JNK were also increased in both undifferentiated ( $\sim 6.4$ fold) and differentiated ( $\sim 1.3$ fold) SMA ES cells when compared to control ES cells. Up-regulation of phosphorylated JNK was previously seen in primary muscle cultures derived from SMA patients, although total levels of this protein were reduced in these cells [45]. Another cell stress-response protein that is often found in stress granules where SMN is seen to localize [46,47], TIA-1, was also up-regulated in SMA ES cells $(\sim 2$ fold for undifferentiated cells and $\sim 1.5$ folds for differentiated cells). Activated in response to FAS ligand stimulation, TIA-1 appears to function as a mediator of apoptotic cell death [48]. Protein disulfide isomerase was down-regulated in SMA ES cells, but the vast majority of chaperones and ER stress-related proteins were not changed (Figure 7). Levels of p53, Bax, Bad, and Puma were also not affected in SMA ES cells (Figure 9).

Cellular stress-response protein p21 is up-regulated in both SMN-deficient ES cells and in spinal cords of SMA transgenic mice

The tumor suppressor protein p21 Waf1/Cip1 acts as an inhibitor of cell-cycle progression. It has been shown that p21 is induced in response to a variety of stress signals, including genotoxins, oxidants, and metabolic perturbation [49]. Western blot analyses show that levels of p21 are increased in both undifferentiated and differentiated SMA ES cells (Figure 10A). In differentiated control cells, p21 is expressed at very low levels but is increased by as much as $41.7 \pm 0.3$ fold ( $\mathrm{n}=4$ independent experiments, $p<0.05$, Student's $t$-test) in differentiated SMA cells. By contrast, the expression of another member of the Cip/Kip family of cyclin-dependent kinase inhibitors, p27, was unaffected (Figure 10A). p21 is also up-regulated in spinal tissue obtained from SMA transgenic mice compared to spinal tissue from control mice $(17.1 \pm 0.2$ fold, $p<0.01$, Student's $t$-test, Figure 10B).

\section{Discussion}

In this study, we have developed an improved protocol for in vitro motor neuron differentiation using GFP expression as a readout in the control ES line (HBG3, HB9::eGFP) [31]. This protocol employs a multi-step process that involves priming ES cells with Noggin and FGFs prior to addition of signaling molecules RA and SAG (Figure 1). Using this modified procedure, we were able to generate a motor neuron population in vitro with high efficiency ( $50 \%)$. The differentiated ES cells acquired immunohistochemical features of motor neurons as evidenced by expression of neuronal and motor neuron markers (Figure 2). We also derived ES cells from a severe transgenic SMA mouse for differentiation to provide a cell-culture model for type I SMA. Applying this method to SMA ES cells, we were able to 


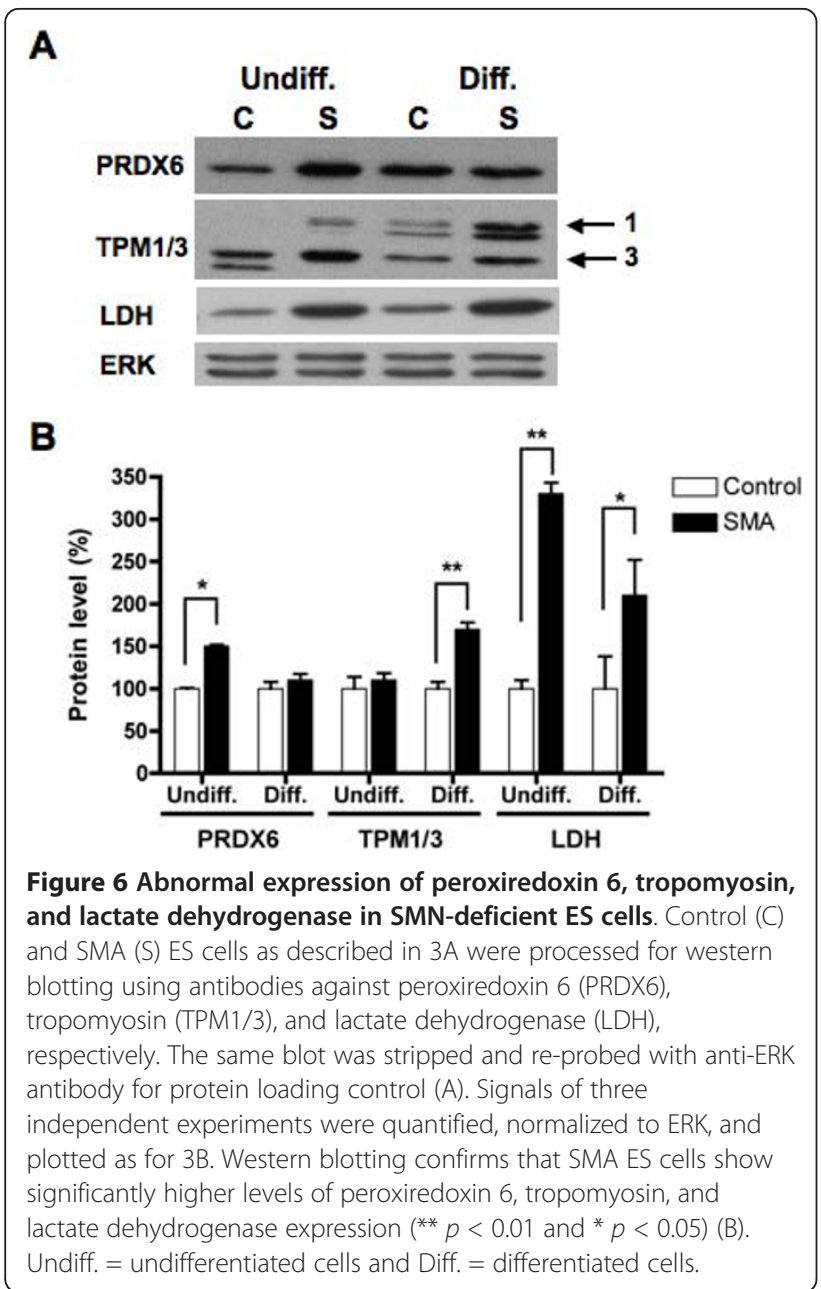

perform proteomic analyses to identify pathways affected in both undifferentiated and differentiated SMA ES cells.

Differentiation efficiency of control and SMA ES cells were similar, but our study shows that several pathways involved in cell stress-response, energy metabolism, protein turnover, and cytoskeleton stability are affected by low expression of SMN (Table 1). Interestingly, similar disturbances in these pathways have been reported in other proteomic studies using different proteomic approaches that were conducted in SMN-deficient cells and tissues other than motor neurons [41,42,45,50,51].

Although motor neurons are the primary cells affected in SMA, most studies use alternative tissues or cell cultures because of difficulties in obtaining motor neurons from affected animals. Antibodies detect proteins with higher specificity and sensitivity, but such studies are restricted by availability of suitable antibodies for blotting or antibody arrays. By comparison, comparative twodimensional SDS-PAGE difference gel electrophoresis and iTRAQ analyses can be used to provide unbiased analysis

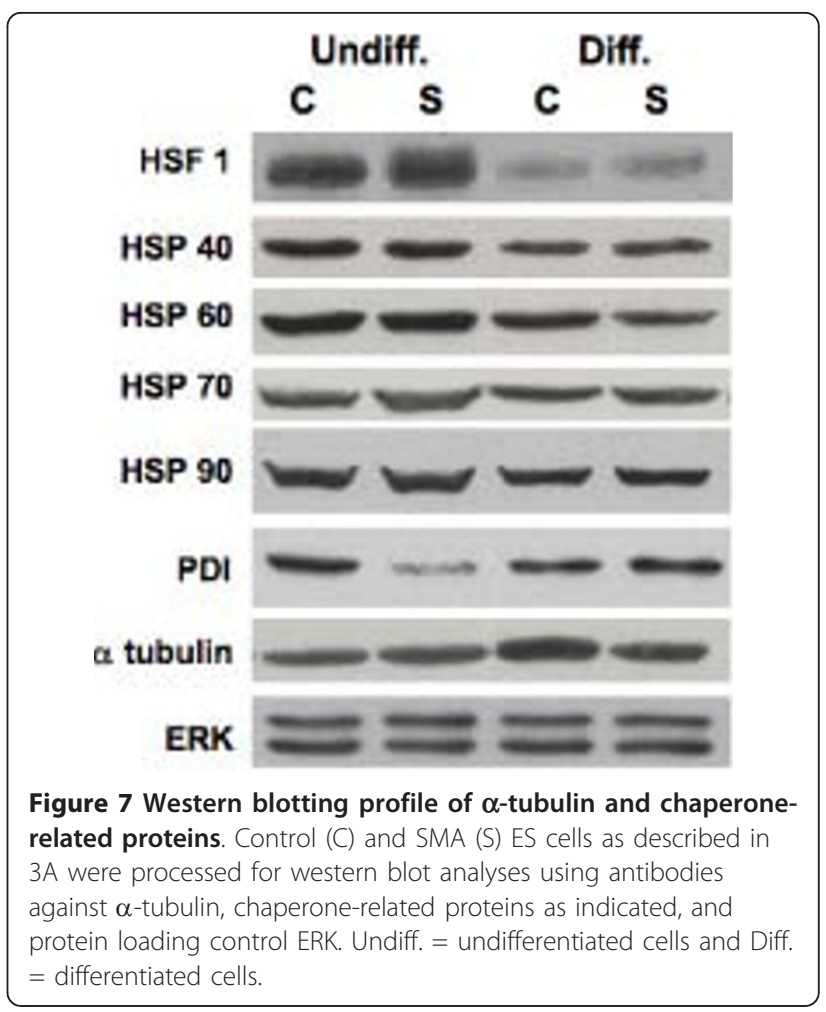

of protein changes. For iTRAQ expression, differences are determined from alterations in quantities of the tags used to label discrete populations of peptides derived from proteins isolated from control and affected cells or tissues. This requires all peptides to be identified by LC/MS/MS. For gel systems, differences in quantities of dye-tagged proteins are determined, and only differentially expressed proteins need to be processed for identification by MS/ MS. We detected 1900 spots using two-dimensional SDSPAGE compared to an iTRAQ study with SMA fibroblasts that detected 2171 proteins [50]. In both techniques, quantification of less-abundant proteins is less accurate. Among dysregulated proteins that are involved in cellular metabolism, we confirmed up-regulation of lactate dehydrogenase in SMA ES cells by western blotting (Figure 6). Lactate dehydrogenase is an oxidoreductase of the glycolysis pathway that catalyses the interconversion of pyruvate and lactate with concomitant interconversion of NADH and NAD+ [52]. Aberrant expression of lactate dehydrogenase and other energy metabolism enzymes (e.g., glyoxalase 1, brain creatine kinase, aldehyde dehydrogenase) in SMA cells could disturb energy production and consumption, and contribute to the pathology of SMA. Consistent with our findings, mRNAs encoding several enzymes of glycolysis are aberrantly expressed in muscles derived from SMA patients [53].

In our proteomic analyses, we also found up-regulation of tropomyosin in differentiated SMA ES cells 
(Table 1, Figure 6). A similar finding was reported in the hippocampus of Smn-/-; SMN2+/+ mice [42]. Tropomyosin is a dimeric coiled-coil protein that binds along the length of actin filaments. In non-muscle cells, tropomyosin stabilizes cytoskeleton actin filaments [54]. Thus, dysregulation of tropomyosin could compromise actin dynamics and cytoskeleton stability. Levels of other actin binding proteins have been proposed to play a role in SMA. Profilin II, the small actin-binding protein that associates with SMN [55,56], is up-regulated in both SMN-depleted PC12 cells and cells from an SMA mouse model $[57,58]$. The actin bundling protein Plastin 3 has recently been identified as a protective, gender-specific modifier of SMA and is associated with SMN and actin in a large protein complex [59]. Together, these findings implicate a role for disruption of actin cytoskeletal dynamics in SMA pathogenesis.

Up-regulation of peroxiredoxin 6 in SMA ES cells (Table 1 and Figure 6), and increased expression of peroxiredoxin protein in SMA mouse tissue [42], implicates cell stress-responses in SMA. Peroxiredoxin 6 is an antioxidant enzyme that reduces levels of $\mathrm{H}_{2} \mathrm{O}_{2}$ to protect cells from oxidative injury [60]. Up-regulation of peroxiredoxin 6 could be a compensatory response to potentially increased oxidative stress in SMN-deficient cells. Reduced levels of SMN have been shown to cause mitochondrial dysfunction [61], which can initiate oxidative stress. Expression of peroxiredoxin 6 is also increased in a mutant SOD1 mouse model of amyotrophic lateral

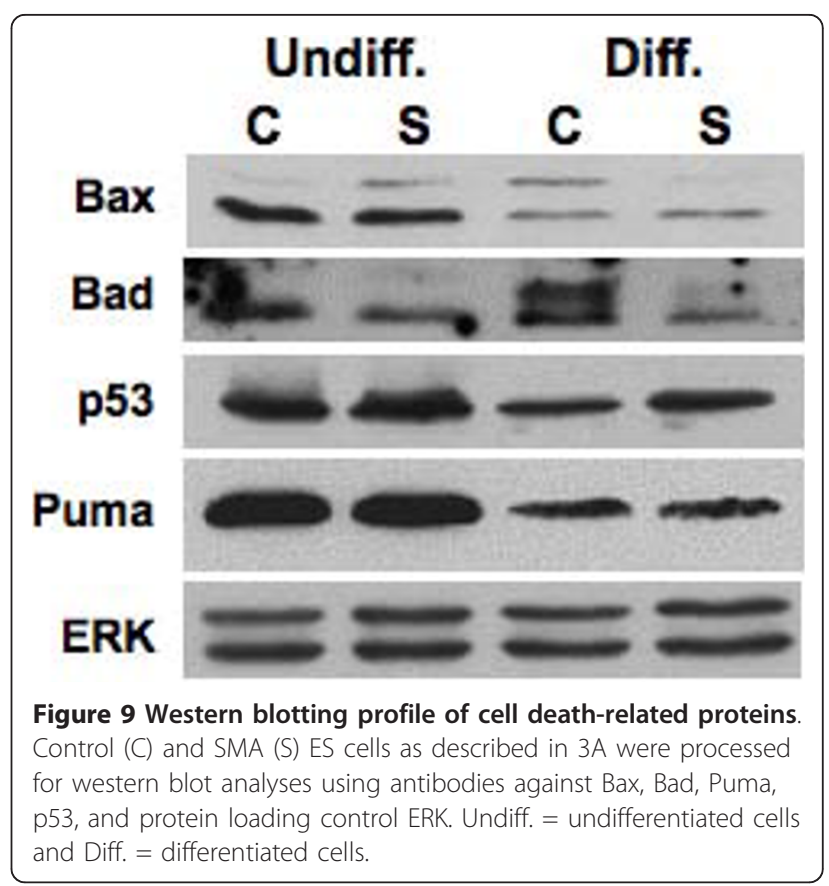

sclerosis [62]. Interestingly, over-expression of SMN protects cells against cell death induced by mutant SOD1 under oxidative stress [63]. To investigate the notion that SMN deficiency might lead cells in stress in more detail, we used western blotting to show that activation of the p38 MAP kinase and JNK pathways were increased in both undifferentiated and differentiated

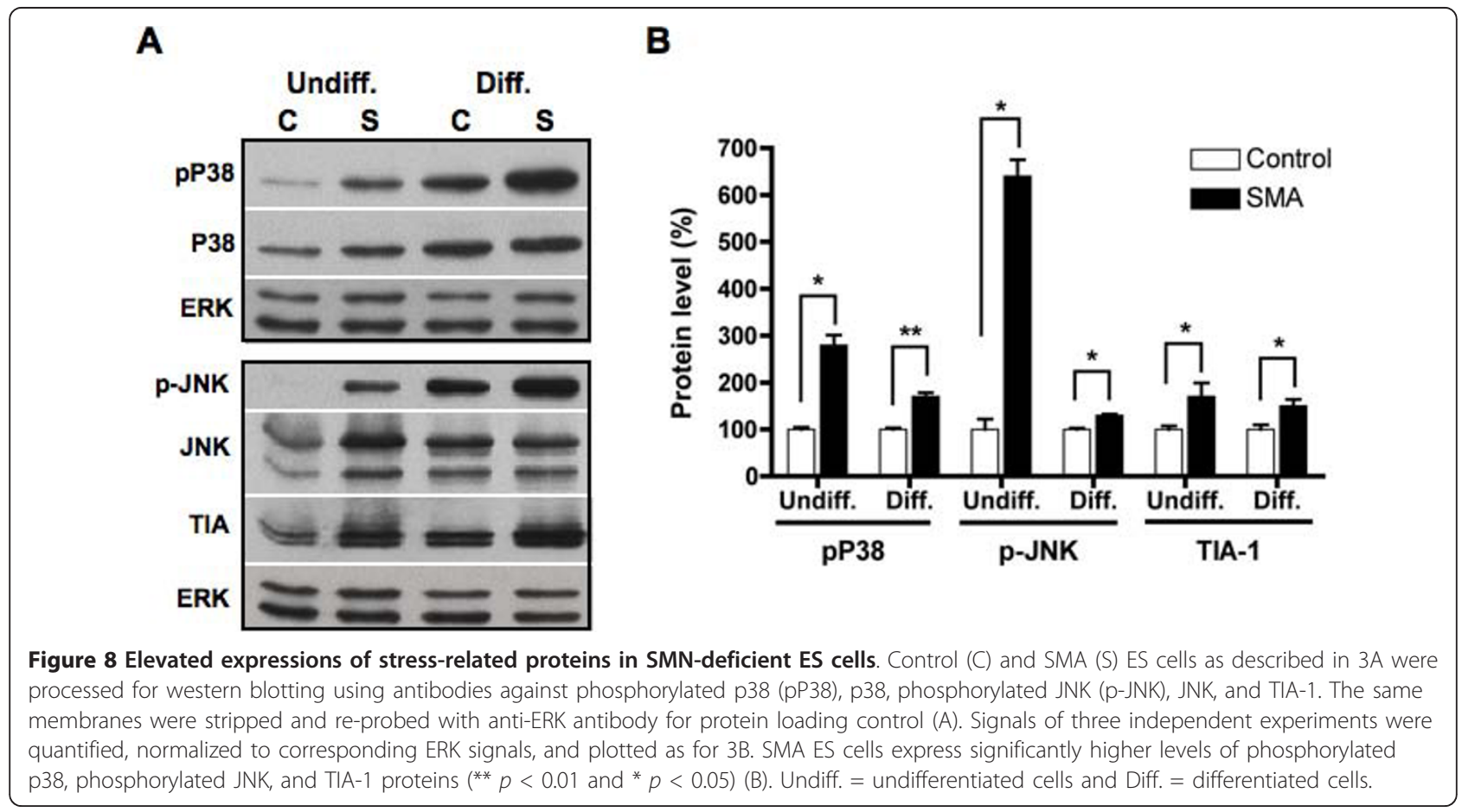




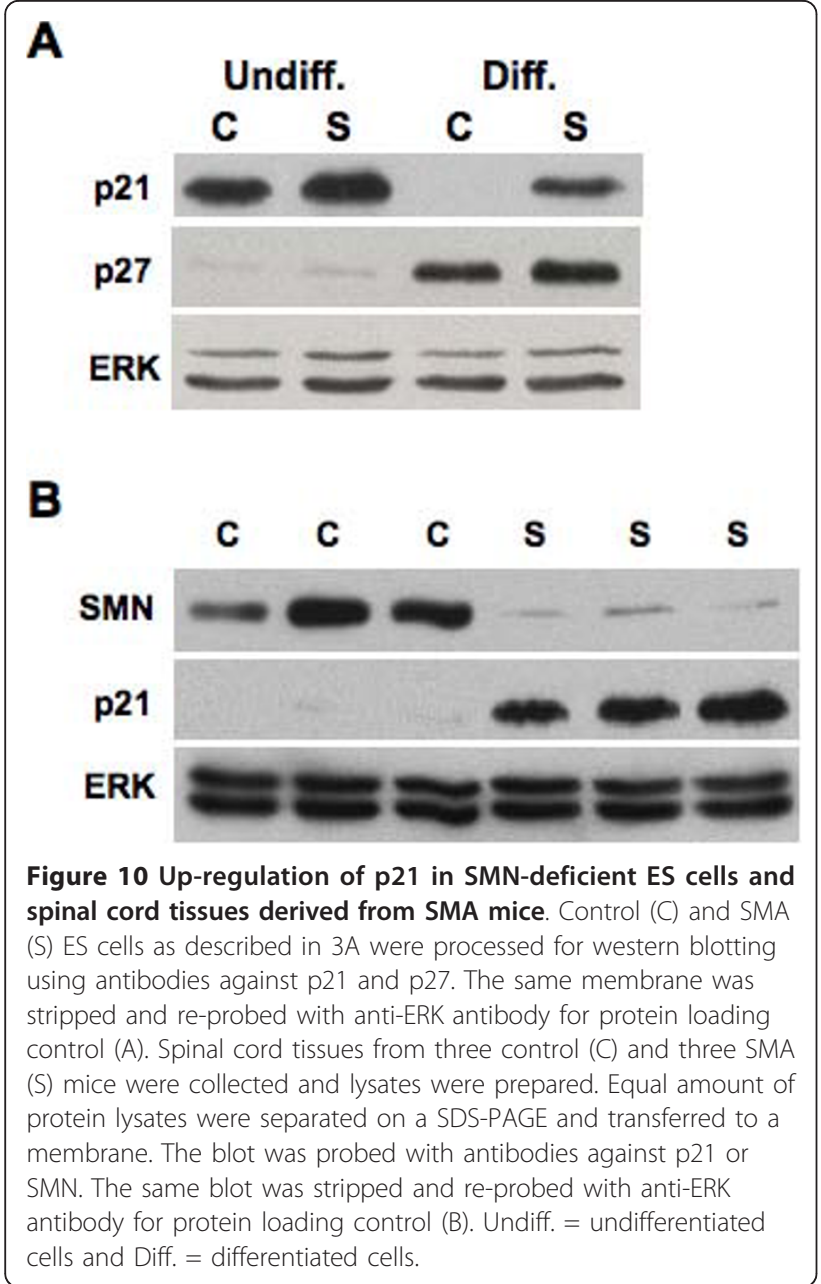

SMA ES cells (Figure 8). Both of these pathways have been implicated in neuronal cell death by activating apoptotic pathways in response to heat and osmotic shock, genotoxic damage, X-ray and UV radiation, and proinflammatory cytokines $[64,65]$. We also showed that the stress-response protein TIA-1 is increased in SMA ES cells (Figure 8). TIA-1 is often localized in stress granules where SMN is seen to locate [47]. Notably, expression of the stress-response protein p21 is increased significantly in both SMA ES cells and spinal cord tissues of a mouse model of SMA (Figure 10). We could not determine whether disease progression affects p21 expression because we were unable to recover sufficient spinal cord samples from different aged SMA mice. Although p21 expression is higher in undifferentiated SMA cells than in undifferentiated control cells, the differences are much more striking in the differentiated cells. Up-regulation of p21 is a cellular response to stress that leads to cell growth arrest and favors cell survival [66], but prolonged stress in SMA cells will eventually lead to cell death. Transcription factors such as $\mathrm{p} 53, \mathrm{Sp} 1, \mathrm{p} 300, \mathrm{CEBP} \beta$, and Stats induce expression of the p21 gene [49,67]. However, as p53 levels are not altered in SMN-deficient cells (Figure 9), it is unlikely that up-regulation of p21 is mediated by this transcription factor in SMN-deficient cells. Thus, the mechanism by which SMN deficiency leads to up-regulation of p21 is not yet clear.

Our analyses show a number of pathways that are dysregulated in SMA ES cells but the most important may be induction of cell stress. This cell stress might explain why we see significantly reduced numbers of SMA ES cells compared to control ES cells 5 days after differentiation (C. Wu, D. Whye, W. Wang, unpublished data) and why motor neurons are particularly sensitive to SMN deficiency in SMA patients. Stress-induced cell death is more pronounced in fibroblasts derived from SMA patients compared to age-matched controls [68], and regulation of SMN expression directly influences cell survival [69-72]. Modulation of levels of downstream effectors of cell death such as pro-apoptotic Bax and the antiapoptotic factor Bcl- $\mathrm{x}_{\mathrm{L}}$ in SMA mice directly impacts the disease phenotype and lifespan of SMA mice $[73,74]$. All these studies support the hypothesis that SMN plays an active role in cell survival. The recent groundbreaking discovery that human fibroblasts can be reprogrammed into an ES cell-like state has significantly advanced the field of stem cell and neurodegenerative disease research. Therefore, it will be of great interest to determine if the similar pathways are aberrantly regulated in the induced pluripotent stem cells derived from SMA fibroblasts.

\section{Conclusion}

We have derived SMN-deficient ES cells from a severe transgenic SMA mouse which represent a cell-culture model of SMA. Our work indicates that lower expression of SMN activates cellular stress pathways and causes a dysregulation of energy metabolism, protein degradation, and cytoskeleton stability.

\section{Methods}

Embryonic stem cell culture

HBG3 ES cells were derived from a HB9::GFP ( $m$ HB9$G f p 1 b)$ transgenic mouse as previously reported [31], and control $(S M N 2+/+; S m n+/+)$ and SMA (SMN2+/+; Smn-/-) murine ES cells were derived from a SMA transgenic mouse (FVB.Cg-Tg(SMN2)89Ahmb Smn1 $1^{\text {tm1Msd } / J) ~}$ [25] using similar techniques. All mice were obtained from Jackson Laboratories, Bar Harbor, ME, USA. All procedures involving animals for deriving ES cells were performed in conformity with the guidelines of the National Institutes of Health and were approved by the Johns-Hopkins University Institutional Animal Care and Use Committee (approved protocol number: MO06M240). 
Embryonic stem cells were expanded on feeder layers of primary mouse embryonic fibroblasts (PMEF, hygro-resistant, passage 3, PMEF-H; Millipore, Billerica, MA, USA) in $100-\mathrm{mm}$ tissue culture dishes. Cells were cultured with ES cells growth medium containing DMEM supplemented with 15\% fetal bovine serum (FBS, Stem Cell Technologies, Vancouver, BC, Canada), 1\% GlutaMax-I supplement, 1\% MEM non-essential amino acids, $1 \%$ nucleosides, 0.1 mM $\beta$-mercaptoethanol, $1 \%$ penicillin/streptomycin, and 1 $\mu \mathrm{l} / \mathrm{ml}$ murine leukemia inhibitor factor (Millipore). Whenever possible, stem-cell grade reagents were used for ES cell culture.

\section{Differentiation of ES cells into motor neurons}

Embryonic stem cells on fibroblast feeder layers were dissociated with $0.25 \%$ trypsin/EDTA and plated onto $0.1 \%$ gelatin-coated tissue culture flasks. Fibroblasts were allowed to re-attach to the flask, and then the floating ES cell population was collected. Approximately $2 \times 10^{6}$ cells were plated into $100-\mathrm{mm}$ petri dishes containing 10 $\mathrm{ml}$ of neural differentiation priming medium containing DMEM supplemented with 15\% FBS, 1\% MEM nonessential amino acids, 1\% GlutaMax-I supplement, 1\% penicillin/streptomycin, $1 \mathrm{mM}$ monothio-glycerol, $50 \mathrm{ng} /$ $\mathrm{ml}$ Noggin (Invitrogen, Carlsbad, CA, USA), $20 \mathrm{ng} / \mathrm{ml}$ bFGF (Invitrogen), and $20 \mathrm{ng} / \mathrm{ml} \mathrm{FGF-8} \mathrm{(Invitrogen)} \mathrm{for}$ EB formation. Media were replaced daily. After two days, aggregated EBs were re-suspended in motor neuron differentiation medium (NITSf) containing basal medium A supplemented with $10 \%$ knockout serum replacement (Invitrogen), 1\% N-2 supplement, 1\% ITS-B supplement (Stem Cell Technologies), 1\% ascorbic acid, 1\% penicillin/streptomycin, $0.1 \mathrm{mM} \beta$-mercaptoethanol, 0.5\% GlutaMax-I supplement, 30\% D-glucose, $20 \mu \mathrm{g} / \mathrm{ml}$ heparin (Sigma, St. Louis, MO, USA) and $50 \mu \mathrm{g} / \mathrm{ml}$ fibronectin (Stem Cell Technologies) in the presence of $1 \mu \mathrm{M}$ RA (Sigma) and $1 \mu \mathrm{M}$ SAG (Calbiochem, Gibbstown, NJ, USA). Media were replaced daily. After 5 days of induction with RA and SAG, EBs were collected, washed with phosphate-buffered saline (PBS), and dissociated in Accumax (Millipore) following the manufacturer's protocol. Cell aggregates were depleted from dissociated EBs by filtering through a BD cell strainer. Single cells were then suspended in NITSf medium supplemented with $10 \mathrm{ng} / \mathrm{ml}$ of each BDNF, GDNF, CNTF, and NT-3 and plated at a concentration of $1 \times 10^{5}$ cells per well of 24 well plates that contained poly-DL-ornithine hydrobromide (Sigma)/laminin (Millipore)/matrigel- (BD Bioscience, San Jose, CA, USA) coated coverslips.

\section{Comparative two-dimensional SDS-polyacrylamide gel electrophoresis and mass spectrometry analysis}

Undifferentiated and differentiated control and SMA ES cells were lysed in $30 \mathrm{mM}$ Tris, $\mathrm{pH} 8.5$ containing $7 \mathrm{M}$ urea, $2 \mathrm{M}$ thiourea, and 4\% CHAPS. Lysates were cleared by centrifuging at $12,000 \times \mathrm{g}$ at $4^{\circ} \mathrm{C}$ for $10 \mathrm{~min}$. A portion of each sample supernatant was pooled together to create an internal standard. Individual samples were labeled with CyDye DIGE Fluor minimal labeling dyes (GE Healthcare, Piscataway, NJ, USA) at a ratio of $200 \mathrm{pmol}$ Cydye per $50 \mu \mathrm{g}$ protein according to manufacturer's protocols. For each experiment, two control and two SMA samples were labeled with Cy3, and another two control and two SMA samples were labeled with Cy5. This dye swap was performed to negate any dye preference artifacts in analysis. The internal standard protein pool was labeled with Cy2. Equal portions of control, SMA, and internal standard were mixed and loaded onto IPG strips (BioRad, Hercules, CA, USA) via rehydration in the presence of the same lysis buffer (see above) containing 0.5\% Pharmalyte 3-10 (BioRad). Samples from undifferentiated ES cells were run on $\mathrm{pH}$ 3-10 linear IPG strips, while differentiated samples were run on pH 3-10 non-linear IPG strips. After isoelectric focusing, IPG strips were equilibrated for $15 \mathrm{~min}$ with 75 mM Tris, pH 8.8, 6 M Urea, 30\% Glycerol, 2\% SDS, and $65 \mathrm{mM}$ DTT followed by $15 \mathrm{~min}$ with $75 \mathrm{mM}$ Tris, pH 8.8, 6 M Urea, 30\% Glycerol, 2\% SDS, and $135 \mathrm{mM}$ iodoacetamide (Sigma). The IPG strips were loaded onto $10 \%$ SDS-PAGE gels, and proteins were separated by electrophoresis and imaged using a Typhoon Trio Scanner (GE Healthcare). Changes in levels of individual protein spots were determined using Decyder 6.5 software (GE Healthcare). Statistical significance of the change was determined using a paired, two-tailed Student's $t$ test. Spots were ranked according to p-values. Spots with a $t$-test $\mathrm{p}$-value of less than 0.05 and an average ratio greater than or less than 1.5 were picked and trypsin digested.

Peptide identities were determined by mass spectrometry. Matrix-assisted laser desorption ionization timeof-flight mass spectrometry (MALDI TOF MS) was carried out on a 4800 MALDI TOF/TOF Analyzer (Applied Biosystems, Atlanta, GA, USA). Peptide mass fingerprint (PMF) spectra were obtained in positive ion reflector mode with internal calibration for each sample. Four peaks from each spectrum were selected and subjected to further fragmentation for sequence information via tandem MS (MS/MS) with default calibration. Using the search program Mascot (v2.2, Matrix Sciences), PMF and MS/MS spectra were submitted for database searches with the following parameters: NCBInr database, trypsin enzyme, 1 maximum missed cleavage, oxidation of methionines, carbamidomethylation of cysteines, $75 \mathrm{ppm}$ precursor mass tolerance, and $0.3 \mathrm{Da}$ MS/MS fragment mass tolerance. Only protein matches with a probability score below the significance threshold $(p<0.05)$ were considered. 


\section{Immunocytochemistry and western blot analysis}

Immunocytochemistry and western blot analyses were performed as previously described [68,75]. In brief, differentiated ES cells were washed in PBS, fixed with $4 \%$ paraformaldehyde in PBS for $10 \mathrm{~min}$, and permeabilized in $0.1 \%$ NP-40 in PBS for 15 min. After two washes with $1 \times$ PBS, cells were blocked in 5\% BSA in Tris-buffered saline containing $0.05 \%$ Tween-20 (TBS-T) for $1 \mathrm{hr}$ at room temperature and then incubated overnight at $4^{\circ} \mathrm{C}$ with mouse anti-Islet-1 (1:50, 39.4D5, Developmental Studies Hybridoma Bank, Iowa City, IA, USA), goat anti-choline acetyltransferase (1:200, Millipore), or chicken anti-neurofilament (1:200, Millipore). After washing three times with TBS-T, the cells were incubated with donkey antimouse Texas Red, donkey anti-chicken Texas Red, or donkey anti-goat DyLight 549. All secondary antibodies were purchased from Jackson ImmunoResearch (West Grove, PA, USA). Slides were mounted in Vectashield containing DAPI (Vector Laboratories, Burlingame, CA, USA).

For western blotting, spinal cord samples were collected at P2-5 from the same colonies of transgenic mice used to derive control and SMA ES cells (see above). All procedures involving animals for collecting spinal cord tissues were performed in conformity with the guidelines of the National Institutes of Health and were approved by the Nemours/Alfred I. duPont Hospital for Children Institutional Animal Care and Use Committee (approved protocol number: NBR-2008003). Prior to tissue harvesting, the genotype of SMA pups were determined by standard PCR (Jackson laboratories). Lysates from spinal cord tissues and ES cells were prepared, protein concentrations were measured using the BCA assay, and western blot analyses were performed as previously described $[68,75]$. In brief, $50 \mu \mathrm{g}$ of total protein lysates were resolved by 10\% SDS-PAGE and transferred to nitrocellulose membranes. The membranes were probed with the following antibodies: neurofilament (1:500, Millipore), ChAT (1:500, Millipore), Hb9 (1:10,000, Abcam, Cambridge, MA, USA), SMN (1:1000, BD Biosciences), Gemin2 (2E17, 1:1000, Abcam), peroxiredoxin 6 (1:1000, Abcam), lactate dehydrogenase (1:5000, Abcam), tropomyosin 1/3 (1:1000, Cell Signaling, Danvers, MA, USA), p38, p-p38, JNK, p-JNK (1:1000, Cell Signaling), p21 (1:500, Cell Signaling), p27 (1:2500, BD Bioscience), TIA-1 (1:500, Santa Cruz, Santa Cruz, CA, USA), and Erk (1:10,000, Santa Cruz). The blots were then incubated with the appropriate secondary HRPconjugated antibodies, and proteins were detected using enhanced chemiluminescence (GE Healthcare). Signals were quantified, and ratios of proteins of interest to Erk were calculated as previously described $[68,75]$. Statistical analyses were determined using a paired, two-tailed Student's $t$-test (GraphPad Prism software, La Jolla, CA). P-values less than 0.05 were considered to be statistically significant.

\section{Acknowledgements}

We are indebted to Dr. Jeffery Twiss for critical comments on this work. This work was supported by Nemours, a grant (2 P20 RR016472-10) under the INBRE program of the National Center for Research Resources (NCRR), and a COBRE grant award from the NIH (5 P20 RR020173-04) to support the Center for Pediatric Research at the Alfred I. duPont Hospital for Children, Wilmington, Delaware, USA.

\section{Author details}

${ }^{1}$ Department of Biological Science, University of Delaware, Newark, DE, USA. 2Department of Pediatrics, Columbia University Medical Center, New York, NY, USA. ${ }^{3}$ Nemours Biomedical Research, Nemours/Alfred I. duPont Hospital for Children, Wilmington, DE, USA. ${ }^{4}$ Delaware Biotechnology Institute, Newark, DE, USA. ${ }^{5}$ Experimental Neurology, Biogen Idec, Cambridge, MA, USA. ${ }^{6}$ Department of Pediatrics, Thomas Jefferson University, Philadelphia, PA, USA.

\section{Authors' contributions}

CW bred mice, collected and genotyped spinal cord samples, performed immunofluorescence studies of differentiated ES cells, and participated in writing the manuscript. DW developed the protocol for ES cell differentiation and participated in western blot analyses and manuscript writing. LG and RWM carried out proteomic work including 2D SDS-PAGE analyses, spot picking, and trypsin digestion. DK contributed ES cells. LC and KHL conducted mass spectrometry studies. WW participated in western blot analyses, overall design of the study, and the writing of the manuscript. All authors read and approved the final manuscript.

\section{Competing interests}

The authors declare that they have no competing interests.

Received: 3 November 2010 Accepted: 8 March 2011

Published: 8 March 2011

\section{References}

1. Pearn J: Incidence, prevalence, and gene frequency studies of chronic childhood spinal muscular atrophy. J Med Genet 1978, 15(6):409-413.

2. Lunn MR, Wang CH: Spinal muscular atrophy. Lancet 2008, 371(9630):2120-2133.

3. Crawford TO, Pardo CA: The neurobiology of childhood spinal muscular atrophy. Neurobiol Dis 1996, 3(2):97-110.

4. Pearn J: Classification of spinal muscular atrophies. Lancet 1980, 1(8174):919-922.

5. Lefebvre $S$, Burglen $L$, Reboullet $S$, Clermont $O$, Burlet $P$, Viollet $L$, Benichou B, Cruaud C, Millasseau P, Zeviani M, et al: Identification and characterization of a spinal muscular atrophy-determining gene. Cell 1995, 80:155-165.

6. Lorson $\mathrm{CL}$, Hahnen $\mathrm{E}$, Androphy EJ, Wirth $\mathrm{B}$ : A single nucleotide in the SMN gene regulates splicing and is responsible for spinal muscular atrophy. Proc Natl Acad Sci USA 1999, 96(11):6307-6311.

7. Monani UR, Lorson CL, Parsons DW, Prior TW, Androphy EJ, Burghes AH, McPherson JD: A single nucleotide difference that alters splicing patterns distinguishes the SMA gene SMN1 from the copy gene SMN2. Hum Mol Genet 1999, 8(7):1177-1183.

8. Paushkin S, Gubitz AK, Massenet S, Dreyfuss G: The SMN complex, an assemblyosome of ribonucleoproteins. Curr Opin Cell Biol 2002, 14(3):305-312.

9. Pellizzoni L: Chaperoning ribonucleoprotein biogenesis in health and disease. EMBO Rep 2007, 8(4):340-345.

10. Burghes $A H$, Beattie $C E$ : Spinal muscular atrophy: why do low levels of survival motor neuron protein make motor neurons sick? Nat Rev Neurosci 2009, 10(8):597-609.

11. Carissimi C, Saieva L, Baccon J, Chiarella P, Maiolica A, Sawyer A, Rappsilber J, Pellizzoni L: Gemin8 is a novel component of the survival motor neuron complex and functions in small nuclear ribonucleoprotein assembly. J Biol Chem 2006, 281(12):8126-8134. 
12. Carissimi C, Baccon J, Straccia M, Chiarella P, Maiolica A, Sawyer A, Rappsilber J, Pellizzoni L: Unrip is a component of SMN complexes active in snRNP assembly. FEBS Lett 2005, 579(11):2348-2354.

13. Gabanella F, Butchbach ME, Saieva L, Carissimi C, Burghes AH, Pellizzoni L: Ribonucleoprotein assembly defects correlate with spinal muscular atrophy severity and preferentially affect a subset of spliceosomal snRNPs. PLOS ONE 2007, 2(9):e921.

14. Zhang Z, Lotti F, Dittmar K, Younis I, Wan L, Kasim M, Dreyfuss G: SMN deficiency causes tissue-specific perturbations in the repertoire of snRNAs and widespread defects in splicing. Cell 2008, 133(4):585-600.

15. Zhang HL, Pan F, Hong D, Shenoy SM, Singer RH, Bassell GJ: Active transport of the survival motor neuron protein and the role of exon-7 in cytoplasmic localization. J Neurosci 2003, 23(16):6627-6637.

16. Rossoll W, Jablonka S, Andreassi C, Kroning AK, Karle K, Monani UR, Sendtner M: Smn, the spinal muscular atrophy-determining gene product, modulates axon growth and localization of beta-actin mRNA in growth cones of motoneurons. J Cell Biol 2003, 163(4):801-812.

17. McWhorter ML, Monani UR, Burghes AH, Beattie CE: Knockdown of the survival motor neuron (Smn) protein in zebrafish causes defects in motor axon outgrowth and pathfinding. J Cell Biol 2003, 162(5):919-931.

18. Winkler C, Eggert C, Gradl D, Meister G, Giegerich M, Wedlich D, Laggerbauer B, Fischer U: Reduced U snRNP assembly causes motor axon degeneration in an animal model for spinal muscular atrophy. Genes Dev 2005, 19(19):2320-2330.

19. Cifuentes-Diaz C, Nicole S, Velasco ME, Borra-Cebrian C, Panozzo C, Frugier T, Millet G, Roblot N, Joshi V, Melki J: Neurofilament accumulation at the motor endplate and lack of axonal sprouting in a spinal muscular atrophy mouse model. Hum Mol Genet 2002, 11(12):1439-1447.

20. Murray LM, Comley LH, Thomson D, Parkinson N, Talbot K, Gillingwater TH: Selective vulnerability of motor neurons and dissociation of pre- and post-synaptic pathology at the neuromuscular junction in mouse models of spinal muscular atrophy. Hum Mol Genet 2008, 17(7):949-962.

21. Kariya S, Park GH, Maeno-Hikichi Y, Leykekhman O, Lutz C, Arkovitz MS, Landmesser LT, Monani UR: Reduced SMN protein impairs maturation of the neuromuscular junctions in mouse models of spinal muscular atrophy. Hum Mol Genet 2008, 17(16):2552-2569.

22. McGovern VL, Gavrilina TO, Beattie CE, Burghes AH: Embryonic motor axon development in the severe SMA mouse. Hum Mol Genet 2008, 17:2900-2909.

23. Kong $L$, Wang $X$, Choe DW, Polley $M$, Burnett BG, Bosch-Marce $M$, Griffin JW, Rich MM, Sumner CJ: Impaired synaptic vesicle release and immaturity of neuromuscular junctions in spinal muscular atrophy mice. J Neurosci 2009, 29(3):842-851.

24. Le TT, Pham LT, Butchbach ME, Zhang HL, Monani UR, Coovert DD, Gavrilina TO, Xing L, Bassell GJ, Burghes AH: SMNDelta7, the major product of the centromeric survival motor neuron (SMN2) gene, extends survival in mice with spinal muscular atrophy and associates with fulllength SMN. Hum Mol Genet 2005, 14(6):845-857.

25. Monani UR, Sendtner M, Coovert DD, Parsons DW, Andreassi C, Le TT, Jablonka S, Schrank B, Rossol W, Prior TW, Morris GE, Burghes AH: The human centromeric survival motor neuron gene (SMN2) rescues embryonic lethality in $\mathrm{Smn}(-/-)$ mice and results in a mouse with spinal muscular atrophy. Hum Mol Genet 2000, 9(3):333-339.

26. Monani UR, Pastore MT, Gavrilina TO, Jablonka S, Le TT, Andreassi C, DiCocco JM, Lorson C, Androphy EJ, Sendtner M, Podell M, Burghes AH: A transgene carrying an $A 2 G$ missense mutation in the $S M N$ gene modulates phenotypic severity in mice with severe (type I) spinal muscular atrophy. J Cell Biol 2003, 160(1):41-52.

27. Park GH, Kariya S, Monani UR: Spinal muscular atrophy: new and emerging insights from model mice. Curr Neurol Neurosci Rep 2010, 10(2):108-117.

28. Christou YA, Moore HD, Shaw PJ, Monk PN: Embryonic stem cells and prospects for their use in regenerative medicine approaches to motor neurone disease. Neuropathol Appl Neurobiol 2007, 33(5):485-498.

29. Orlacchio A, Bernardi G, Martino S: Stem cells: an overview of the current status of therapies for central and peripheral nervous system diseases. Curr Med Chem 2010, 17(7):595-608.

30. Harper JM, Krishnan C, Darman JS, Deshpande DM, Peck S, Shats I, Backovic S, Rothstein JD, Kerr DA: Axonal growth of embryonic stem cellderived motoneurons in vitro and in motoneuron-injured adult rats. Proc Natl Acad Sci USA 2004, 101(18):7123-7128.

31. Wichterle H, Lieberam I, Porter JA, Jessell TM: Directed differentiation of embryonic stem cells into motor neurons. Cell 2002, 110(3):385-397.
32. Xu L, Yan J, Chen D, Welsh AM, Hazel T, Johe K, Hatfield G, Koliatsos VE: Human neural stem cell grafts ameliorate motor neuron disease in SOD1 transgenic rats. Transplantation 2006, 82(7):865-875.

33. Gao J, Coggeshall RE, Tarasenko Yl, Wu P: Human neural stem cell-derived cholinergic neurons innervate muscle in motoneuron deficient adult rats. Neuroscience 2005, 131(2):257-262.

34. Deshpande DM, Kim YS, Martinez T, Carmen J, Dike S, Shats I, Rubin LL, Drummond J, Krishnan C, Hoke A, Maragakis N, Shefner J, Rothstein JD, Kerr DA: Recovery from paralysis in adult rats using embryonic stem cells. Ann Neurol 2006, 60(1):32-44.

35. Sinha S, Chen JK: Purmorphamine activates the Hedgehog pathway by targeting Smoothened. Nat Chem Biol 2006, 2(1):29-30.

36. Li XJ, Hu BY, Jones SA, Zhang YS, Lavaute T, Du ZW, Zhang SC: Directed differentiation of ventral spinal progenitors and motor neurons from human embryonic stem cells by small molecules. Stem Cells 2008, 26(4):886-893.

37. Lamb TM, Harland RM: Fibroblast growth factor is a direct neural inducer, which combined with noggin generates anterior-posterior neural pattern. Development 1995, 121(11):3627-3636.

38. Storey KG, Goriely A, Sargent CM, Brown JM, Burns HD, Abud HM, Heath JK: Early posterior neural tissue is induced by FGF in the chick embryo. Development 1998, 125(3):473-484.

39. Launay C, Fromentoux V, Shi DL, Boucaut JC: A truncated FGF receptor blocks neural induction by endogenous Xenopus inducers. Development 1996, 122(3):869-880.

40. McMahon JA, Takada S, Zimmerman LB, Fan CM, Harland RM, McMahon AP Noggin-mediated antagonism of BMP signaling is required for growth and patterning of the neural tube and somite. Genes Dev 1998, 12(10):1438-1452.

41. Hsu SH, Lai MC, Er TK, Yang SN, Hung CH, Tsai HH, Lin YC, Chang JG, Lo YC, Jong YJ: Ubiquitin carboxyl-terminal hydrolase L1 (UCHL1) regulates the level of SMN expression through ubiquitination in primary spinal muscular atrophy fibroblasts. Clin Chim Acta 2010, 411(23-24):1920-1928.

42. Wishart TM, Huang JP, Murray LM, Lamont DJ, Mutsaers CA, Ross J, Geldsetzer P, Ansorge O, Talbot K, Parson SH, Gillingwater TH: SMN deficiency disrupts brain development in a mouse model of severe spinal muscular atrophy. Hum Mol Genet 2010, 19(21):4216-4228.

43. Ichijo H: From receptors to stress-activated MAP kinases. Oncogene 1999, 18(45):6087-6093.

44. Kyriakis JM, Avruch J: Mammalian mitogen-activated protein kinase signal transduction pathways activated by stress and inflammation. Physiol Rev 2001, 81(2):807-869.

45. Anderson K, Potter A, Baban D, Davies KE: Protein expression changes in spinal muscular atrophy revealed with a novel antibody array technology. Brain 2003, 126(Pt 9):2052-2064.

46. Anderson P: TIA-1: structural and functional studies on a new class of cytolytic effector molecule. Curr Top Microbiol Immunol 1995, 198:131-143.

47. Hua Y, Zhou J: Survival motor neuron protein facilitates assembly of stress granules. FEBS Lett 2004, 572(1-3):69-74.

48. Tian Q, Taupin J, Elledge S, Robertson M, Anderson P: Fas-activated serine/ threonine kinase (FAST) phosphorylates TIA-1 during Fas-mediated apoptosis. J Exp Med 1995, 182(3):865-874.

49. Jung YS, Qian Y, Chen X: Examination of the expanding pathways for the regulation of p21 expression and activity. Cell Signal 2010, 22(7):1003-1012

50. Fuller HR, Man NT, Lam le T, Shamanin VA, Androphy EJ, Morris GE: Valproate and bone loss: iTRAQ proteomics show that valproate reduces collagens and osteonectin in SMA cells. J Proteome Res 2010, 9(8):4228-4233.

51. Wen HL, Lin YT, Ting CH, Lin-Chao S, Li H, Hsieh-Li HM: Stathmin, a microtubule-destabilizing protein, is dysregulated in spinal muscular atrophy. Hum Mol Genet 2010, 19(9):1766-1778.

52. Veech RL: The metabolism of lactate. NMR Biomed 1991, 4(2):53-58.

53. Millino C, Fanin M, Vettori A, Laveder P, Mostacciuolo ML, Angelini C, Lanfranchi G: Different atrophy-hypertrophy transcription pathways in muscles affected by severe and mild spinal muscular atrophy. BMC Med 2009, 7:14.

54. Lin JJ, Eppinga RD, Warren KS, McCrae KR: Human tropomyosin isoforms in the regulation of cytoskeleton functions. Adv Exp Med Biol 2008, 644:201-222. 
55. Giesemann T, Rathke-Hartlieb S, Rothkegel M, Bartsch JW, Buchmeier S, Jockusch BM, Jockusch $\mathrm{H}$ : A role for polyproline motifs in the spinal muscular atrophy protein SMN. Profilins bind to and colocalize with smn in nuclear gems. J Biol Chem 1999, 274(53):37908-37914.

56. Sharma A, Lambrechts A, Hao le T, Le TT, Sewry CA, Ampe C, Burghes AH, Morris GE: A role for complexes of survival of motor neurons (SMN) protein with gemins and profilin in neurite-like cytoplasmic extensions of cultured nerve cells. Exp Cell Res 2005, 309(1):185-197.

57. Bowerman M, Shafey D, Kothary R: Smn depletion alters profilin II expression and leads to upregulation of the RhoA/ROCK pathway and defects in neuronal integrity. J Mol Neurosci 2007, 32(2):120-131.

58. Bowerman M, Anderson CL, Beauvais A, Boyl PP, Witke W, Kothary R: SMN profilin lla and plastin 3: a link between the deregulation of actin dynamics and SMA pathogenesis. Mol Cell Neurosci 2009, 42(1):66-74

59. Oprea GE, Krober S, McWhorter ML, Rossoll W, Muller S, Krawczak M, Bassell GJ, Beattie CE, Wirth B: Plastin 3 is a protective modifier of autosomal recessive spinal muscular atrophy. Science 2008, 320(5875):524-527

60. Chen JW, Dodia C, Feinstein SI, Jain MK, Fisher AB: 1-Cys peroxiredoxin, a bifunctional enzyme with glutathione peroxidase and phospholipase $\mathrm{A} 2$ activities. J Biol Chem 2000, 275(37):28421-28427.

61. Acsadi G, Lee I, Li X, Khaidakov M, Pecinova A, Parker GC, Huttemann M: Mitochondrial dysfunction in a neural cell model of spinal muscular atrophy. J Neurosci Res 2009, 87(12):2748-2756.

62. Strey CW, Spellman D, Stieber A, Gonatas JO, Wang X, Lambris JD, Gonatas NK: Dysregulation of stathmin, a microtubule-destabilizing protein, and up-regulation of $\mathrm{Hsp} 25, \mathrm{Hsp} 27$, and the antioxidant peroxiredoxin 6 in a mouse model of familial amyotrophic lateral sclerosis. Am J Pathol 2004, 165(5):1701-1718.

63. Zou T, llangovan R, Yu F, Xu Z, Zhou J: SMN protects cells against mutant SOD1 toxicity by increasing chaperone activity. Biochem Biophys Res Commun 2007, 364(4):850-855.

64. Morrison RS, Kinoshita Y: The role of p53 in neuronal cell death. Cell Death Differ 2000, 7(10):868-879.

65. Takeda K, Ichijo H: Neuronal p38 MAPK signalling: an emerging regulator of cell fate and function in the nervous system. Genes Cells 2002, 7(11):1099-1111.

66. Dotto GP: p21(WAF1/Cip1): more than a break to the cell cycle? Biochim Biophys Acta 2000, 1471(1):M43-56.

67. Gartel AL, Tyner AL: Transcriptional regulation of the $\mathrm{p} 21((\mathrm{WAF} 1 / \mathrm{CIP} 1)$ gene. Exp Cell Res 1999, 246(2):280-289.

68. Wang W, Dimatteo D, Funanage VL, Scavina M: Increased susceptibility of spinal muscular atrophy fibroblasts to camptothecin-induced cell death. Mol Genet Metab 2005, 85(1):38-45.

69. Ilangovan R, Marshall WL, Hua Y, Zhou J: Inhibition of apoptosis by ZVAD-fmk in SMN-depleted S2 cells. J Biol Chem 2003, 278(33):30993-30999.

70. Vyas S, Bechade C, Riveau B, Downward J, Triller A: Involvement of survival motor neuron (SMN) protein in cell death. Hum Mol Genet 2002, 11(22):2751-2764.

71. Trulzsch B, Garnett C, Davies K, Wood M: Knockdown of SMN by RNA interference induces apoptosis in differentiated P19 neural stem cells. Brain Res 2007, 1183:1-9.

72. Parker GC, Li X, Anguelov RA, Toth G, Cristescu A, Acsadi G: Survival motor neuron protein regulates apoptosis in an in vitro model of spinal muscular atrophy. Neurotox Res 2008, 13(1):39-48.

73. Tsai MS, Chiu YT, Wang SH, Hsieh-Li HM, Lian WC, Li H: Abolishing Baxdependent apoptosis shows beneficial effects on spinal muscular atrophy model mice. Mol Ther 2006, 13(6):1149-1155.

74. Tsai LK, Tsai MS, Ting CH, Wang SH, Li H: Restoring Bcl-x(L) levels benefits a mouse model of spinal muscular atrophy. Neurobiol Dis 2008.

75. Wu CY, Gomez-Curet I, Funanage VL, Scavina M, Wang W: Increased susceptibility of spinal muscular atrophy fibroblasts to camptothecin is p53-independent. BMC Cell Biol 2009, 10:40

doi:10.1186/1471-2202-12-25

Cite this article as: Wu et al.: Proteomic assessment of a cell model of spinal muscular atrophy. BMC Neuroscience 2011 12:25.

\section{Submit your next manuscript to BioMed Central and take full advantage of:}

- Convenient online submission

- Thorough peer review

- No space constraints or color figure charges

- Immediate publication on acceptance

- Inclusion in PubMed, CAS, Scopus and Google Scholar

- Research which is freely available for redistribution

Submit your manuscript at www.biomedcentral.com/submit 